\title{
Musashi1 as a potential therapeutic target and diagnostic marker for lung cancer
}

\author{
Xiao-Yang Wang ${ }^{1, *}$, Huina Yu ${ }^{2, *}$, R. Ilona Linnoila ${ }^{1}$, Laodong $\mathbf{L i}^{2}$, Dangyu Li ${ }^{3}$, Biwen \\ Mo $^{2}$, Hideyuki Okano ${ }^{4}$, Luiz O. F. Penalva5, and Robert I. Glazer ${ }^{6}$ \\ ${ }^{1}$ Cell and Cancer Biology Branch, Center for Cancer Research, National Cancer Institute, National Institutes of Health, \\ Bethesda, MD, USA \\ 2 Division of Respiratory Diseases, Guilin Medical University Hospital, Guilin, Guangxi, P.R. China \\ ${ }^{3}$ Division of Respiratory Diseases, Nan Xi Shan Hospital, Guilin Medical University Hospital, Guilin, Guangxi, P.R. China \\ ${ }^{4}$ Department of Physiology, Keio University, Tokyo, Japan \\ ${ }^{5}$ Children's Cancer Research Institute, Department of Cell and Structural Biology, University of Texas Health Sciences Center \\ at San Antonio, San Antonio, TX, USA \\ ${ }^{6}$ Department of Oncology, Georgetown University, and Lombardi Comprehensive Cancer Center, Washington, DC, USA \\ * Contributed equally to this work
}

Correspondence to: Robert I. Glazer, email: glazerr@georgetown.edu

Correspondence to: Biwen Mo, email: mobiwen@yahoo.com

Keywords: Musashi1, lung cancer, shRNA, $\beta$-catenin, notch, numb

Received: May 15, 2013, Accepted: May 19, 2013, Published: May 21, 2013

This is an open-access article distributed under the terms of the Creative Commons Attribution License, which permits unrestricted use, distribution, and reproduction in any medium, provided the original author and source are credited.

\section{ABSTRACT:}

Lung cancer remains one of the leading causes of cancer-related deaths worldwide with a 5 -year survival rate of less than $20 \%$. One approach to improving survival is the identification of biomarkers to detect early stage disease. In this study, we investigated the potential of the stem cell and progenitor cell marker, Musashi1 (Msi1), as a diagnostic marker and potential therapeutic target for lung cancer. Functional studies in A549 bronchioalveolar carcinoma and NCI-H520 squamous cell carcinoma cells revealed that Msi1 was enriched in spheroid cultures of tumor cells and in the CD133+ cell population. Downregulation of Msi1 by lentivirus-mediated expression of an Msi1 shRNA reduced spheroid colony proliferation. Growth inhibition was associated with reduced nuclear localization of $\beta$-catenin and inhibition of the processing of intracellular Notch. In primary lung cancer, Msi1 protein expression was elevated in $\mathbf{8 6} \%$ of 202 tissue microarray specimens, and Msi1 mRNA was increased in $\mathbf{8 0} \%$ of 118 bronchoscopic biopsies, including metastatic disease, but was rarely detected in adjacent normal lung tissue and in non-malignant diseased tissue. Msi 1 was expressed in a diffuse pattern in most tumor subtypes, except in squamous cell carcinomas, where it appeared in a focal pattern in $50 \%$ of specimens. Thus, Msi 1 is a sensitive and specific diagnostic marker for all lung cancer subtypes.

\section{INTRODUCTION}

Lung cancer is the most common cause of cancerrelated mortality worldwide [1], and despite modern diagnostic and therapeutic advances, the 5-year survival rate following resection has improved only in patients diagnosed with early stage disease. At present, only one out of eight patients diagnosed with lung cancer can be effectively treated due to the prevalence of rapidly metastatic disease [2], and therefore, a key aspect of improving survival is the diagnosis of early disease. Lung cancer is often diagnosed by bronchoscopic biopsy, and bronchial brushing and bronchial lavage have been used as adjuncts to bronchoscopy for histological, cytological [3] and molecular [4] analysis. With the advent of genomics and personalized medicine, the diagnosis and 
A
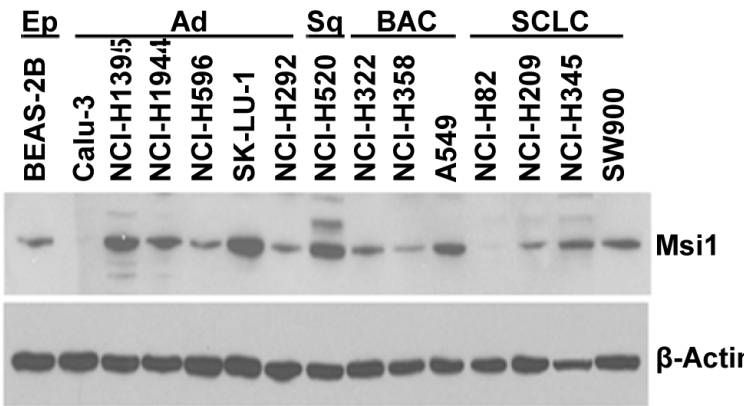

C
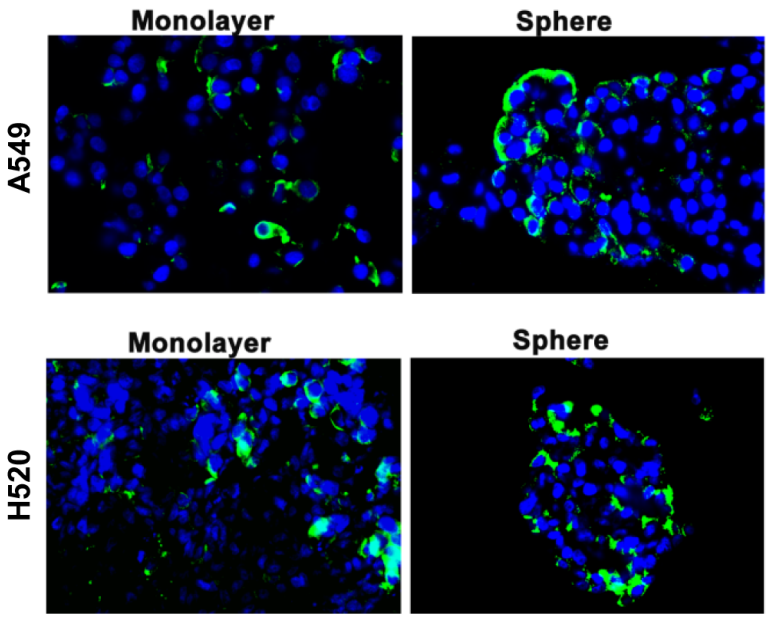

$E$
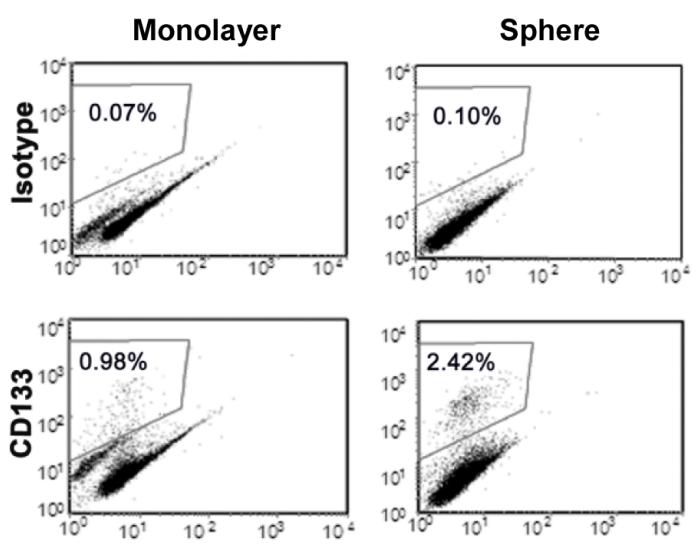

B

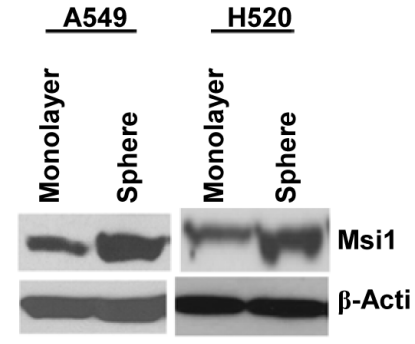

D
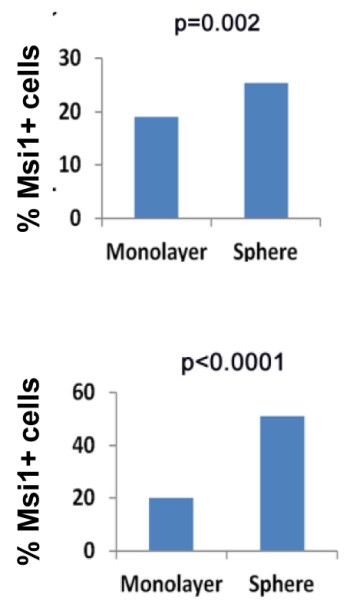

$\mathrm{F}$

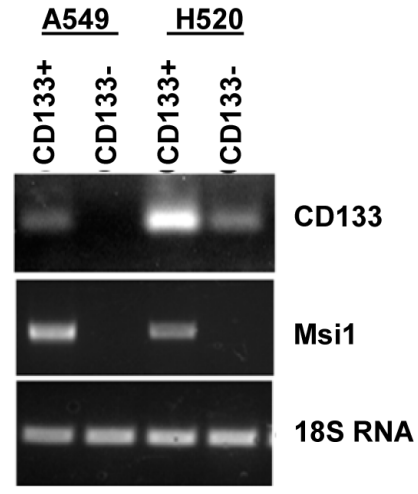

Figure 1: Msi1 expression is enriched in lung cancer stem/progenitor cells. (A) Msi1 expression detected by western blotting is present in 12/14 lung cancer cell lines, as well as in immortalized lung epithelial cell line BEAS-2B. (B) Msil protein expression determined by western blotting is increased in spheroid cultures of A549 and H520 cells vs. monolayer cultures. (C, D) Msi1 expression determined by immunofluorescence is increased in spheroid cultures of A549 and H520 cells vs. monolayer cultures. Msil expression differed significantly between spheroid and monolayer cultures by the two-sided paired $t$ test. Green, Msi1; blue, DAPI. (E) Spheroid cultures express a greater percentage of $\mathrm{CD} 133+$ cells vs. monolayer cultures. (F) CD133-enriched spheroid cultures exhibit greater expression of Msi1 mRNA vs. CD133-negative cells. 


\section{Table 1: Msi1 protein expression} in lung cancer tissue microarray samples. Msil expression was analyzed by IHC. Ad, adenocarcinoma; BAC, bronchioloalveolar carcinoma; AdSq, adenosquamous carcinoma; Sq, squamous cell carcinoma; LCLC, large cell lung carcinoma; SCLC, small cell lung carcinoma; Other, mucoepidermoid carcinoma or malignant mesothelioma. * $\chi 2$ test

\begin{tabular}{|l|c|c|c|}
\hline \multicolumn{1}{|c|}{ Feature } & No. Cases & \% Msi1+ & P -value \\
\hline Age: & & & $0.200^{*}$ \\
\hline$<60$ & 114 & 87 & \\
\hline$\geq 60$ & 98 & 86 & \\
\hline Gender: & & & $0.111^{*}$ \\
\hline Male & 160 & 88 & \\
\hline Female & 42 & 79 & \\
\hline Histology: & & & $0.381^{*}$ \\
\hline Ad & 53 & 81 & \\
\hline BAC & 20 & 95 & \\
\hline Ad-Sq & 4 & 75 & \\
\hline Sq & 81 & 91 & \\
\hline LCLC & 15 & 80 & \\
\hline SCLC & 25 & 80 & \\
\hline Other & 4 & 75 & \\
\hline Total & 202 & 86 & \\
\hline Stage: & & & $0.240^{*}$ \\
\hline I II & 90 & 90 & \\
\hline III IV & 34 & 82 & \\
\hline
\end{tabular}

treatment of lung cancer is expected to improve $[5,6]$.

Musashi1 (Msi1) is an RNA-binding protein that was initially identified in Drosophila melanogaster by its ability to regulate sensory organ development and asymmetric cell division [7, 8]. In mammalian cells, Msi1 regulates translation in stem and progenitor cell populations of several tissues [8-10]. Msi1 is a member of a family of more than 800 RNA-binding proteins that regulate a multitude of processes associated with the posttranscriptional regulation of gene expression, and when aberrantly expressed can lead to diseases such as cancer [11]. Among the documented targets of Msi1-mediated translational repression are Numb, a negative regulator of Notch [12], p21 Wafl, a negative regulator of cyclindependent kinases [13], poly(A) binding protein [14], Doublecortin, a factor involved in neuronal migration [15], Robo3, a protein that controls neural guidance [16] and Apc, a negative regulator of Wnt signaling [17].

\begin{tabular}{|c|c|c|c|}
\hline $\begin{array}{l}\text { Table 2: Ms } \\
\text { cancer bron } \\
\text { Msi1 mRNA } \\
\text { Ad, adenoca } \\
\text { carcinoma; SC } \\
\text { Other, muc } \\
\text { malignant. me }\end{array}$ & $\begin{array}{l}1 \text { mRNA } \\
\text { choscopic } \\
\text { was deter } \\
\text { cinoma; } \\
\text { LC, small } \\
\text { oepidermo } \\
\text { sotheliom }\end{array}$ & $\begin{array}{l}\text { expressio } \\
\text { biopsy s } \\
\text { nined by } \\
\text { Sq, squal } \\
\text { cell lung } \\
\text { d carcil } \\
* x 2 \text { test }\end{array}$ & $\begin{array}{l}\text { in lung } \\
\text { ecimens } \\
\text { RT-PCR } \\
\text { ous cell } \\
\text { rcinoma; } \\
\text { ma or }\end{array}$ \\
\hline Feature & No. Cases & \% Msi1+ & P-value \\
\hline Age: & & & $0.769^{*}$ \\
\hline$<60$ & 54 & 82 & \\
\hline$\geq 60$ & 48 & 79 & \\
\hline Gender: & & & $0.895^{*}$ \\
\hline Male & 84 & 80 & \\
\hline Female & 18 & 78 & \\
\hline Histology: & & & $0.355^{*}$ \\
\hline $\mathrm{Ad}$ & 17 & 77 & \\
\hline $\mathrm{Sq}$ & 47 & 77 & \\
\hline SCLC & 27 & 85 & \\
\hline Other & 11 & 82 & \\
\hline Total & 102 & 80 & \\
\hline Differentiation: & & & $0.889 *$ \\
\hline Well-Moderate & 24 & 75 & \\
\hline Poor & 51 & 77 & \\
\hline Stage: & & & $0.252^{*}$ \\
\hline $\mathrm{I} \sim \mathrm{II}$ & 11 & 64 & \\
\hline III IV & 78 & 83 & \\
\hline
\end{tabular}

A genome-wide analysis of Msil targets revealed $>60$ additional mRNA targets, many of which were related to cancer progression [18]. In malignant tissues, Msi1 is highly expressed in gastric [19], gallbladder [20], colorectal [21], endometrial [22] and lung [23] cancer. In breast cancer [24], increased Msi1 expression correlated with metastatic disease and poor survival.

In addition to its usefulness as a cancer biomarker, Msi1 may serve as a potential therapeutic target. This has been suggested by lentivirus-mediated 'knockdown' (KD) of Msi1 in breast cancer [24, 25] and medulloblastoma cells [26], resulting in inhibition of proliferation and tumor xenograft growth.

In the present study, we report that Msi1 KD in A549 and H520 lung cancer cells inhibited the proliferation of the stem-like spheroid tumor cells that was associated with inhibition of Notch and Wnt signaling. Analyses of lung cancers indicated that Msi1 protein or RNA expression served as a highly sensitive diagnostic marker in $>80 \%$ of $>300$ lung cancers irrespective of histological subtype. 
A
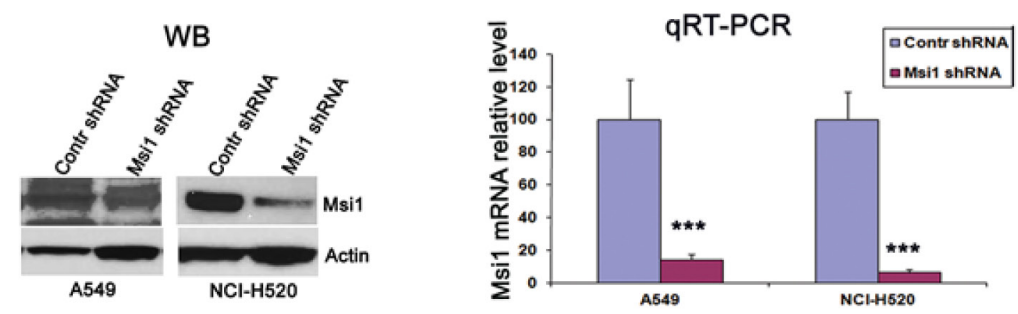

B
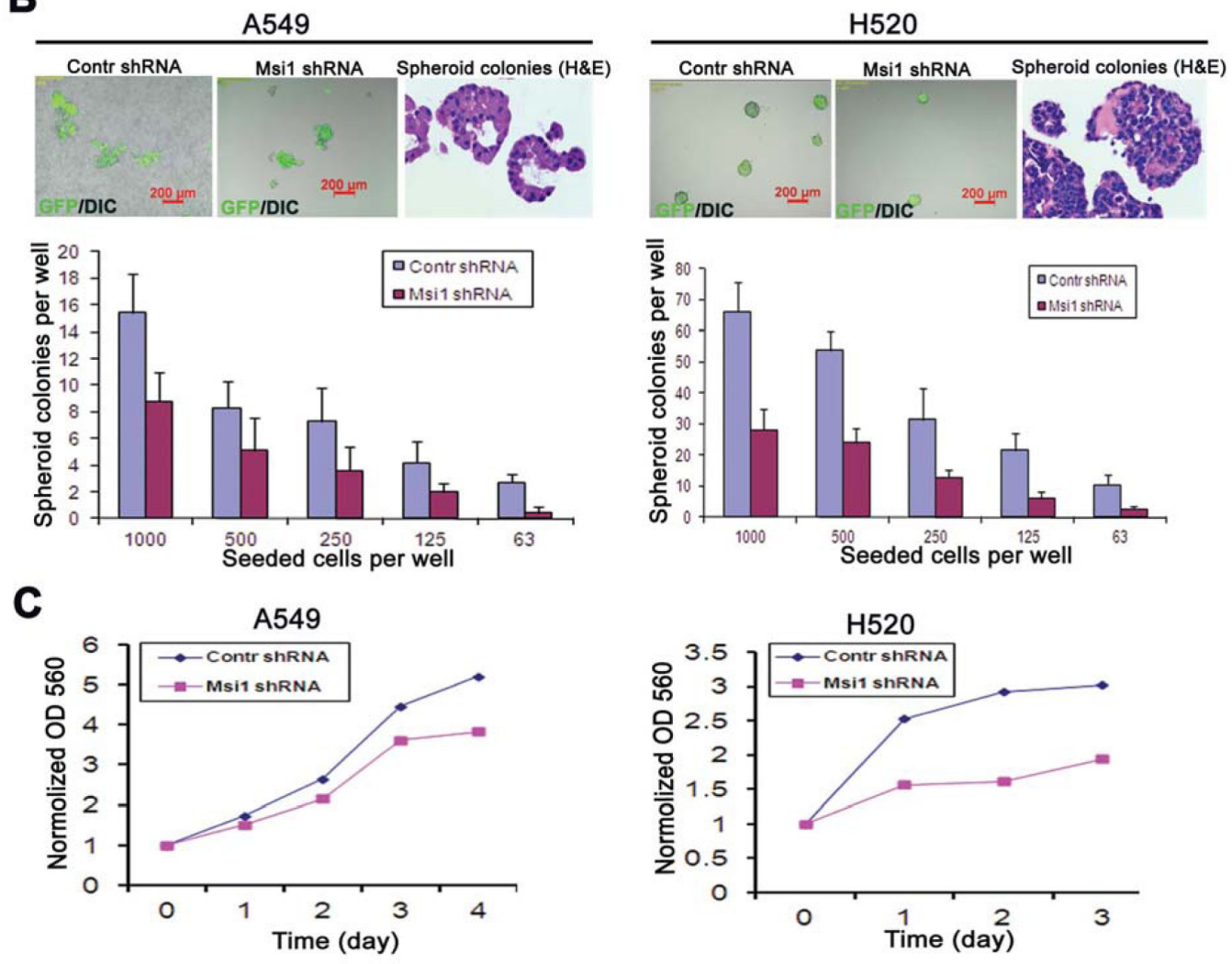

\section{D}
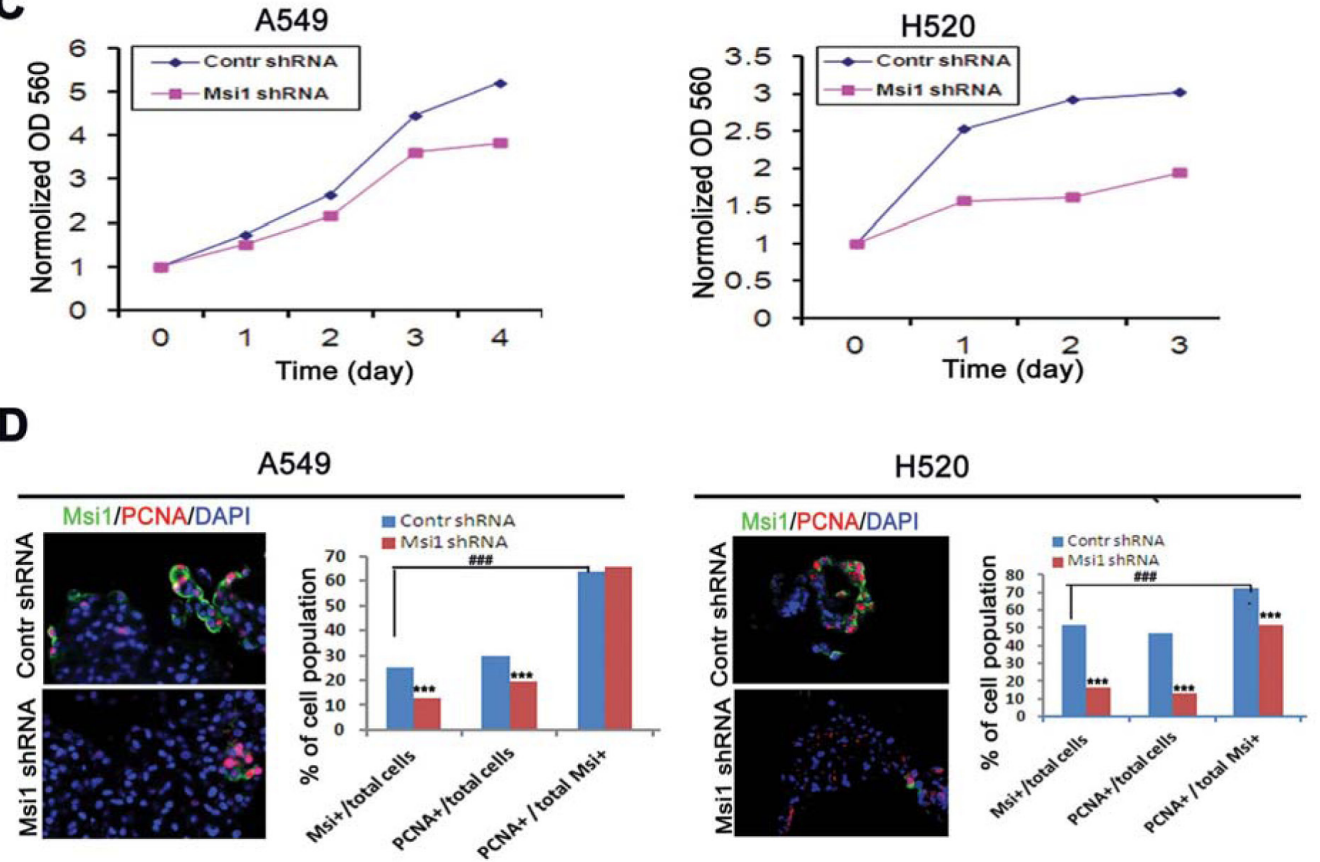

Figure 2: Reduction of Msi1 by RNA interference inhibits spheroid colony formation. (A) Msi1 mRNA levels were "knockeddown" (KD) in A549 and H520 cells by transduction with a lentivirus-expressed shRNA. Left panel, Msi1 protein determined by western blotting. Right panel, Msi1 mRNA levels determined by qRT-PCR showing significant reduction of mRNA expression after transduction by a lentivirus-expressed shRNA vs. control shRNA (two-sided paired t test). (B) Quantitation of spheroid colony formation by detection of GFP fluorescence expressed by the transduced lentivirus. Colony formation was determined in serial dilutions of cells grown for 10 days in ultralow attachment plates in defined serum-free medium. Colony number was significantly decreased in A549 and H520 cells following Msi1 KD. The morphology of colonies of A549 cells resembled glandular epithelium $(H \& E)$, whereas, colonies of H520 cells exhibited a squamous cell carcinoma phenotype. (C) Msi1 KD significantly inhibited the growth of A549 and H520 cells. (D) Msi1 KD significantly reduced the percentage of $\mathrm{Msi1}^{+}$and $\mathrm{PCNA}^{+} \mathrm{A} 549$ and $\mathrm{H} 520$ cells vs. the percentage of $\mathrm{PCNA}^{+}$cells in the total cell population; $\chi 2$ test; $* * * \mathrm{p}<0.0001$ vs. control (Contr) shRNA group; \#\#\# $\mathrm{p}<0.0001$. 


\section{RESULTS}

\section{Msi1 is enriched in spheroid cultures of lung cancer cells.}

Msi1 expression was evaluated by western blotting in 14 lung cancer cell lines and one immortalized airway epithelial cell line (Figure 1A). Msil was expressed in 12/14 lung cancer cell lines, with high levels in about half of them, as well as in the epithelial cell line. To determine if Msi1 was enriched in stem-like cells, A549 and H520 cells were grown as spheroid cultures in defined medium in ultra-low attachment plates or under standard conditions as monolayers. Spheroid cultures contained about a twofold enrichment of Msilin comparison to monolayers (Figure 1B), and detection of Msi1 by immunofluorescence revealed a similar finding (Figure 1C,D). Since CD133 has been widely used as a lung cancer 'stem cell' marker
[27-29], monolayer and spheroid cultures of A549 and H520 cells were sorted for CD133 and Msi1 mRNA levels determined. A representative CD133 profile for A549 cells indicated that CD133+ cells comprised $2.4 \%$ of the cells grown spheroids and $1 \%$ of the cell grown as monolayers (Figure 1E). Analysis of Msi1 RNA levels in CD133+ and CD133- A549 and H520 spheroid cultures indicated that CD133+ cells were enriched for Msi1 mRNA (Figure 1F).

\section{Lentivirus-mediated 'knockdown' of Msi1 inhibits spheroid colony proliferation}

The role of Msi1 in the proliferation of A549 and H520 cells in spheroid culture was examined following lentivirus-mediated expression of an Msil shRNA [24]. RNA interference resulted in reduction of Msi1 protein and $>90 \%$ reduction of Msi1 RNA in A549 and H520 cells in comparison to a control shRNA (Figure 2A), and 10 days post-transduction, $50 \%$ or more inhibition of colony
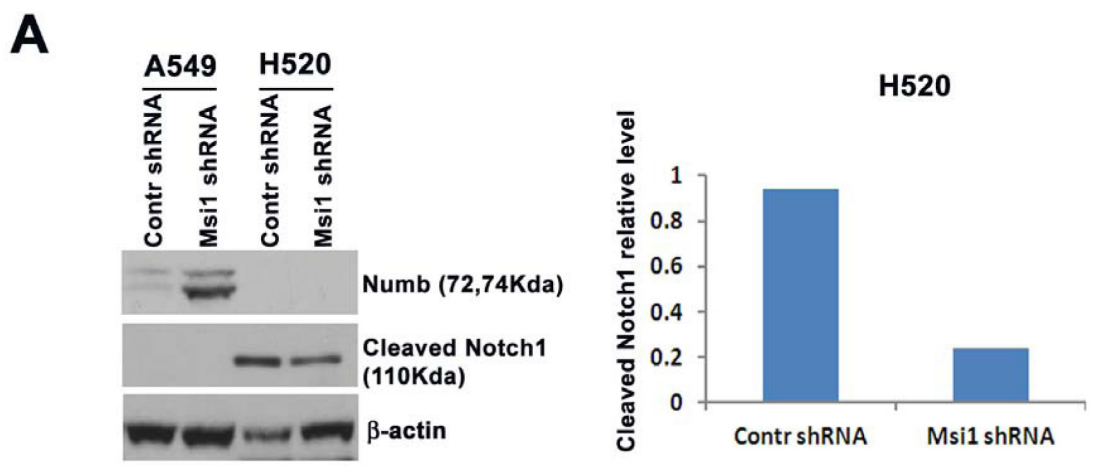

B
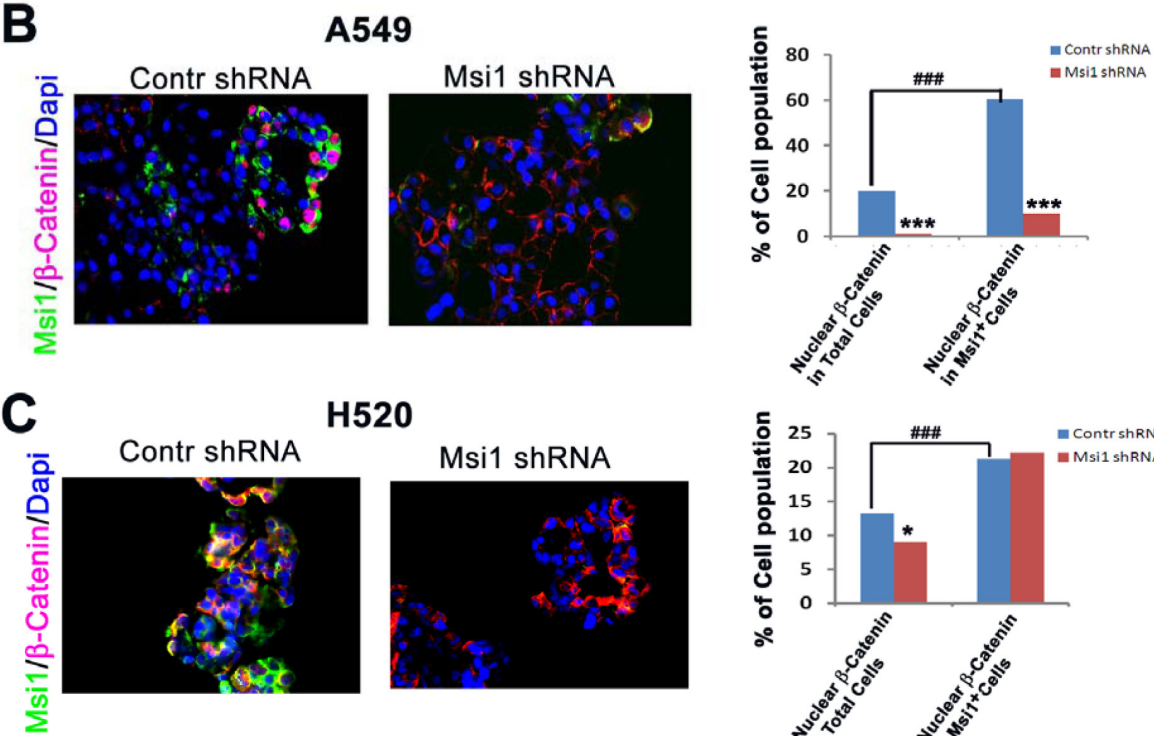

H520
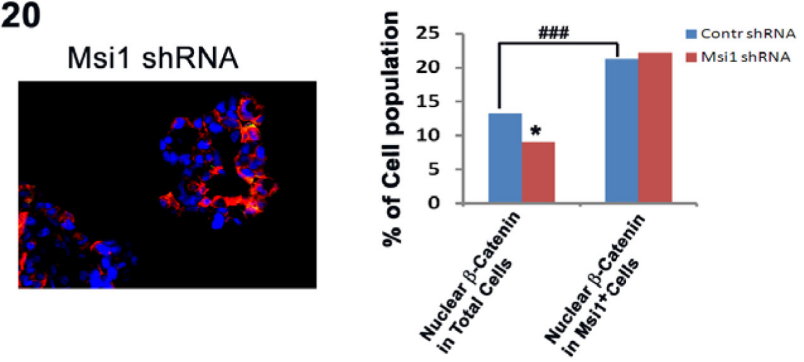

Figure 3: Msi1 KD impairs Notch processing and Wnt pathway activation. (A) Msi1 KD in H520, but not A549 cells reduces intracellular Notch. Numb expression increased in A549 cells following Msi1 KD, but intracellular Notch was below the level of detection. (B) Msi1 KD reduces nuclear $\beta$-catenin translocation in A549 cells and (C) H520 cells. Immunofluorescent staining for Msi1 and $\beta$-catenin indicated significantly greater reduction of nuclear $\beta$-catenin in Msi1+ A549 cells vs. control shRNA-treated cells; $\chi 2$ test, $* \mathrm{p}<0.05, * * *$ $\mathrm{p}<0.0001$. The percentage of nuclear $\beta$-catenin was greater in Msi1+ cells vs. the total cell population; $\chi^{2}$ test, \#\#\# $\mathrm{p}<0.0001$. 
formation was evident in both cell lines (Figure 2B). Interestingly, H520 cells, which resembled a squamous cell morphology, were inhibited to a greater extent than A549 cells, which resembled differentiated glandular cells (Figure 2B, H\&E stained panels). Proliferation of dissociated spheroid cells expressing the Msil shRNA continued to grow at a reduced rate when grown in monolayer culture (Figure 2C). Determination of the coexpression of the proliferation marker PCNA and Msi1 following Msi1 KD revealed that Msi1 and PCNA expression were reduced by $50 \%$ and $31 \%$, and by $69 \%$ and $72 \%$, in A549 and H520 cells, respectively (Figure 2D).

\section{Msi1 KD reduces Notch and Wnt signaling}

Msi1 was previously reported to inhibit Wnt pathway activation, as well as Notch activation through the negative regulator Numb $[12,30]$ in breast cancer and mammary epithelial cells [25]. Following Msi1 $\mathrm{KD}$, there were significant differences in the regulation of these pathways between A549 and H520 cells. A549 and H520 cells responded differently to Msi1 KD with respect to Notch and Wnt signaling. Numb was markedly increased in A549 cells, but was undetectable in H520 cells, whereas, intracellular Notch1 was inhibited in H520 cells and was undetectable in A549 cells (Figure 3A). This suggests that Notch regulation may be more relevant to the growth of H520 cells than A549 cells. Since Numb is a cofactor for Notch ubiquitination [31], it is likely involved in the regulation of another yet to be identified target associated with proliferation. To assess the effects of Msi1 KD on canonical Wnt signaling, cells were analyzed for the nuclear translocation of $\beta$-catenin [32]. Msi1 KD inhibited $\beta$-catenin translocation by $>85 \%$ in Msi1+ A549 cells (Figure 3B), whereas in H520 cells, localization was unaffected (Figure 3C), despite both cells lines having a relatively high percentage of nuclear $\beta$-catenin.

\section{Normal Lung Airway}

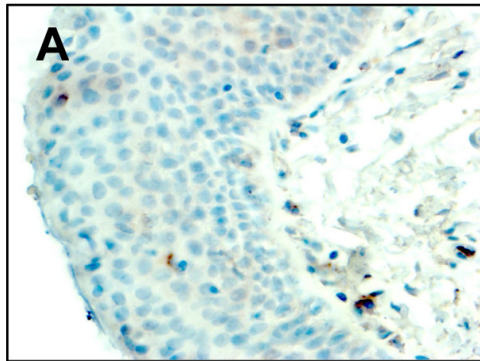

Squamous Carcinoma

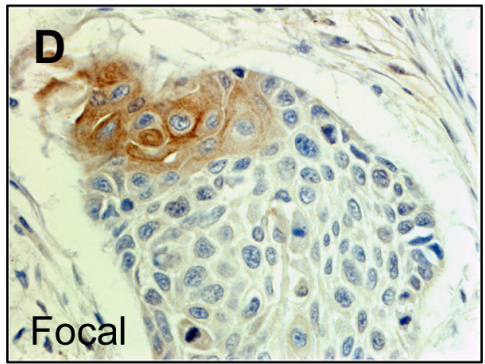

Primary Adenocarcinoma

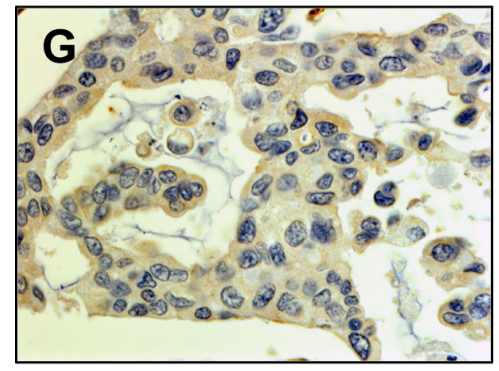

Normal Alveoli

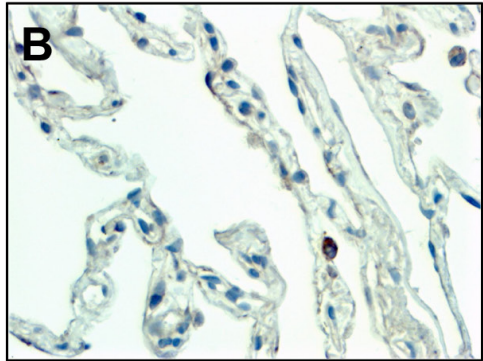

Adenocarcinoma

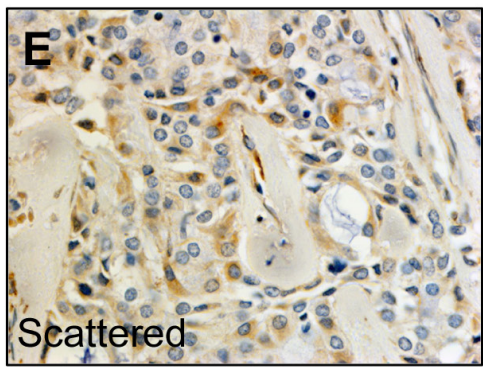

Matched Metastatic Tumor

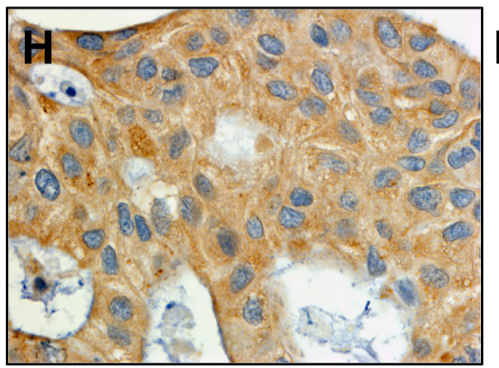

Squamous

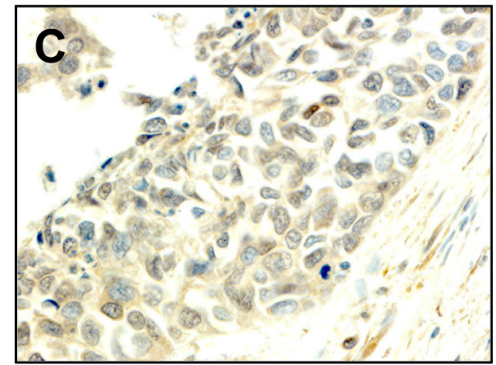

Squamous Carcinoma
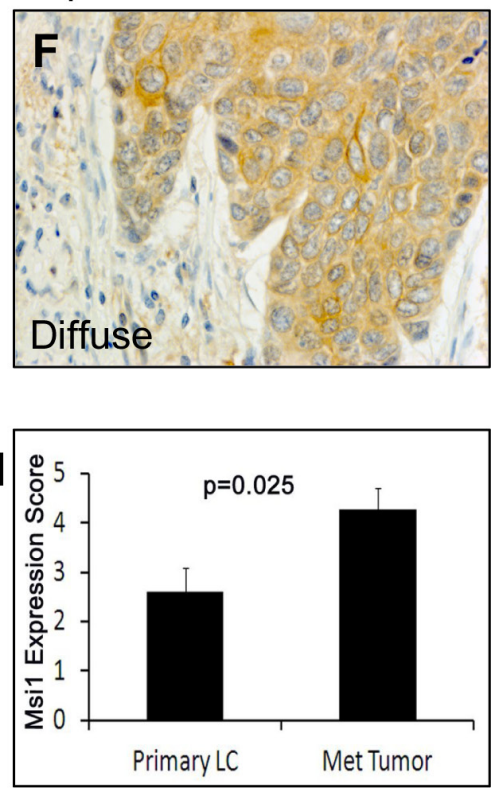

Figure 4: Msi1 expression patterns in lung cancers. (A) Normal airway epithelium contained few Msi1 ${ }^{+}$cells (arrows). (B) Normal lung alveolus did not express Msi1. (C) Negative Msi1 expression in a squamous cell carcinoma. (D) Focal expression of Msil in a squamous cell carcinoma. (E) Scattered Msil expression in an adenocarcinoma. (F) Diffuse Msil expression in a squamous cell carcinoma. (G) Weak Msi1 expression in an adenocarcinoma and (H) high Msil expression in a paired metastatic lesion from (G). (I) Msi1 expression in paired primary and metastatic lung adenocarcinomas. Msil expression was significantly greater in metastatic lesions; two-sided paired t test, $\mathrm{p}=0.025$. 


\section{Expression patterns of Msi1 in human lung cancers.}

To evaluate the usefulness of Msi1 as a lung cancer biomarker, Msi1 localization was examined in nonmalignant and lung cancer tissue microarrays by IHC (Figure 4, Table 1). Msi1 was weakly expressed in scattered cells in airway epithelium (Figure 4A) and was not present in the normal alveolus (Figure 4B). Lung tumors expressed Msi1 in a focal (Figure 4D), scattered (Figure 4E) or diffuse (Figure 4F) pattern in $86 \%$ of 202 lung cancer specimens irrespective of age, gender, histology and stage of disease (Table 1). With the exception of squamous cell carcinomas, $\geq 50 \%$ of tumors expressed Msil in a diffuse pattern (Figure 4F, Supplementary Table 1). Msil was often expressed at higher levels in lung tumor metastases than in the primary tumor, but did not reach statistical significance $(P=0.159$, $\mathrm{N}=15$ ) (Figure 4G-I). Msi1 expression was also assessed by qRT-PCR in 102 lung cancers and 16 non-malignant lung tissues collected by bronchoscopic biopsy (Table 2). Similar to the tissue microarray findings (Table 1), $80 \%$ of lung cancers were Msi1+, irrespective of age, gender, histology, degree of differentiation or stage of disease, but was detectable in only 2 of 16 non-malignant specimens (Supplementary Table 2).

\section{DISCUSSION}

In the present study, we evaluated the role of Msi1 in the proliferation of lung cancer cells and its utility as a diagnostic marker for lung cancers of varying histological subtypes. Msil expression was enriched in A549 and H520 lung cancer cells under cell culture conditions that promoted the formation of less differentiated spheroid colonies shown to be enriched for stem-like cells [33]. Similarly, cells sorted for CD133, a cell population enriched in tumor initiating cells [27-29], were further enriched for Msi1, in agreement with Msi1 as a stem cell or early progenitor cell marker, and consistent with its enrichment in CD133+ breast cancer "mammospheres" [24], and poorly differentiated oral squamous cell carcinomas [34]. Silencing Msil by RNA interference reduced spheroid colony proliferation, implicating Msi1 as a regulator of less differentiated stem-like cells. Thus, Msil expression in lung cancer cells has similar characteristics and function as previously noted for breast cancer [24], medulloblastoma [35], glioblastoma [36, 37] and colon cancer [38,39] cells, and is consistent with the original observation of Msi1 being a marker for neural stem and progenitor cells $[10,40]$.

Msi1 is a positive regulator of Wnt and Notch signaling $[25,41]$ and several other pathways that remain to be explored [18]. A549, but not H520 cells exhibited a marked upregulation of Numb following Msi1 KD, consistent with the suppression of Numb translation by Msi1 [12] as previously observed in mammary epithelial and breast cancer cells [24, 25]. Although Numb was markedly increased by Msi1 KD in A549 cells, intracellular Notch was below detection in both control and Msi1 KD cells, making the association between Numb and Notch inconclusive. The increase in Numb in the presence of reduced Wnt signaling also suggests it is not a TCF/LEF target gene as previously noted [42]. Mechanistically, this could have resulted from a proliferinmediated endocrine pathway as shown in mammary epithelial cells [25] or from blocking the translation of Apc, a negative regulator of canonical Wnt signaling [17]. Thus, Wnt pathway activation due to the nuclear translocation of $\beta$-catenin appears to play a dominant role in the proliferation of Msi1-expressing cells [24, 25, 41].

The majority of primary lung cancer biopsies exhibited varying patterns of Msi1 expression as previously noted in lung cancer specimens [23]. Lung cancer analyzed by tissue microarray or bronchoscopic biopsy expressed Msi1 protein or RNA in $\geq 80 \%$ of tumor specimens regardless of histological subtype. These findings are in general agreement with the report by Moreira et al. [23], although they found little or no Msil expression in large cell lung cancer and 40\% Msi1+ adenocarcinomas. Other than patient variability and a smaller sample size, the reasons for disparity are not obvious. When Msil detection was combined with histopathological examination, the percentage of positive diagnoses was increased from $81 \%$ to $100 \%$ (results not shown), and the higher expression of Msil in metastatic disease may further increase its value as a diagnostic marker. The association between Msil expression in less differentiated lung cancer cells and proliferation also suggests that it may serve as a readily accessible marker of progression or response to therapy if it is present in sputum and bronchial washings from lung cancer patients.

Overall, our study shows that Msil regulates the proliferation of stem-like spheroid lung tumor cells in associated with Notch and Wnt signaling. Analyses of lung cancers indicated that Msi1 protein or RNA expression can serve as a highly sensitive diagnostic marker for lung cancer irrespective of the histological subtype.

\section{MATERIALS AND METHODS}

\section{Cell Lines and Cell Culture}

Human lung cancer cell lines Calu-3, NCI-H1395, NCI-H1944， NCI-H596， SK-LU-1， NCI-H292, NCI-H520， NCI-H322， NCI-H358，A549，NCI-H82, NCI-H209, NCI-H345, SW900, and immortalized human lung epithelial cell line BEAS-2B were obtained from the Tissue Culture Shared Resource, Lombardi 
Comprehensive Cancer Center, Georgetown University. NCI-H520 cells were cultured in RPMI1640 (Invitrogen, Grand Island, NY) supplemented with $10 \%$ fetal bovine serum (FBS) (Invitrogen). A549 cells were maintained in Dulbecco's- modified Eagle's medium (DMEM) (Invitrogen) supplemented with 10\% FBS. All the cells were cultured at $37^{\circ} \mathrm{C}$ under $5 \% \mathrm{CO}_{2}$ in a Forma Series II $\mathrm{CO}_{2}$ incubator (Thermo Scientific, Asheville, NC).

\section{Spheroid Cell Culture}

Spheroid cell culture was carried out in ultra-low attachment plates (Costar, Corning, NY) as described [24]. Briefly, A549 and NCI-H520 cells growing as monolayer cultures were trypsinized with $0.05 \%$ trypsin $-0.5 \mathrm{mM}$ EDTA (Invitrogen), washed twice with PBS, counted and seeded into a 6-well plate at a density of 3,000 viable cells/ $\mathrm{ml}$ or into a 96-well plate at serial dilutions of 1000 to 63 cells per $200 \mu$ l. Cells were grown in serum-free DMEM medium supplemented with 1X B27 (Invitrogen), $20 \mathrm{ng} /$ $\mathrm{ml}$ epidermal growth factor (EGF) (Sigma) and $20 \mathrm{ng} /$ $\mathrm{ml}$ basic fibroblast growth factor (FGF-2) (Invitrogen) at $37^{\circ} \mathrm{C}$ under $5 \% \mathrm{CO}_{2}$. Spheroid clusters were counted and collected by gravity or gentle centrifugation $(800 \mathrm{~g}, 10$ sec) after 10 days, and dissociated in $0.05 \%$ trypsin- 0.5 mM EDTA for 10-15 min by gentle pipetting. Cells were filtered through a 40- $\mu \mathrm{m}$ nylon mesh sieve (Falcon), analyzed microscopically for single cellularity and counted. Successive passages were plated at 1,000 cells/ $\mathrm{ml}$ in 6-well plates. Generation 1 (G1) spheres, grown for 10 days, were fixed with $4 \%$ paraformaldehyde (PFA) for 2 hours, washed once. Spheres were collected, embedded in $4 \%$ agarose gel, and placed on ice for 10 minutes. The spheres were subsequently fixed with 4\% PFA overnight prior to standard histological processing, sectioning, and hematoxylin and eosin (H\&E) staining (American Histolabs Inc., Gaithersburg, MD).

\section{Lentivirus-mediated shRNA Expression}

Msi1 expression was 'knocked down' (KD) using an shRNAmir GIPZ lentiviral vector targeting the sequence, 5'-CGT CCT GTA TCA TAT GTA AAT-3' in the 3'-UTR of Msi1 mRNA (Oligo ID \#V2HS_280120; Open Biosystems, Huntsville, AL) [24]. TLA-HEK293T cells (Open Biosystems) were transfected with the TransLentiviral Packaging Mix and pGIPZ transfer vector at $50 \%$ confluence using Arrest-In transfection reagent (Open Biosystems) according to the manufacturer's protocol. After incubation for 48-72 hr, the virus-containing supernatant was collected and centrifuged at 3,000 rpm for $20 \mathrm{~min}$ at $4^{\circ} \mathrm{C}$, mixed 50:50 with fresh cell culture media, and used to transduce A549 and NCI-H520 cells. Lentivirus expressing a non-silencing control shRNA (shRNAmir, Open Biosystems) served as a negative control. Cells were selected for stable integration of the virus by incubation with $5 \mu \mathrm{g} / \mathrm{ml}$ puromycin (SigmaAldrich Corp. St. Louis, MO) for 10 days. The efficiency of integration was monitored by green fluorescent protein (GFP) co-expressed by the lentivirus.

\section{Growth Assay}

Cells dissociated as a single cell suspension from first generation spheroid colonies were seeded in 96-well plates at 3,000 cells/well in $200 \mu \mathrm{l}$ medium, and growth was determined after 24 to $96 \mathrm{hr}$ by sulforhodamine B staining [25].

\section{Western Blotting}

Western blotting was performed as described [25]. Primary antibodies included rat anti-Msi1 (1:1000) [45] (14H-1, Dr. Hideyuki Okano, Keio University, Tokyo, Japan), rabbit anti-Numb (1:1000, Cell Signaling Technology, Danvers, MA), rabbit anti-Cleaved Notch1 (Val1744) (D3B8) (1:1000, Cell Signaling Technology) and mouse anti- $\beta$-actin (1:3000, Sigma).

\section{Flow Cytometry}

For CD133 detection, A549 and NCI-H520 cells were suspended at a concentration of $0.5-1.0 \times 10^{6}$ cells/ $\mathrm{ml}$ in ice-cold phosphate buffered saline (PBS) containing $3 \%$ fetal bovine serum (PBS/FBS). Cells were sorted with a Becton Dickinson FACSort system for $\mathrm{CD}_{133^{+}}$and CD133-cell populations and analyzed with FCS Express V3 software (De Novo Software, Ontario, Canada) as described [24]. Cells were washed twice with PBS. CD133 and Msi1 mRNA expression were detected by RT-PCR in sorted cells [24].

\section{Dual Label Immunofluorescence}

Spheroid colony slides were deparaffinized in xylene for $15 \mathrm{~min}$, and rehydrated in graded ethanol solutions for $5 \mathrm{~min}$ each. Antigen retrieval was achieved by steaming slides for $10 \mathrm{~min}$ in $10 \mathrm{mM}$ citrate buffer, pH 6.0. Dual label immunofluorescence was performed as previously described [25]. Primary antibodies were mouse monoclonal anti-human proliferating cell nuclear antigen (PCNA) (1:100, Dako North America, Inc. Carpentaria, CA), rabbit anti-beta-catenin (1:50, eBioscience, San Diego, CA), and anti-biotinylated Msi1 [45]. Antigens were retrieved as described above, and detected sequentially on sections by incubation for $1 \mathrm{hr}$ with the first (Msi1) primary antibody followed by incubation with the appropriate FITC-conjugated streptavidin (eBioscience), followed by incubation for $1 \mathrm{hr}$ 
with the second primary antibody followed by incubation with Alexa Fluor ${ }^{\circledR}$ 594-conjugated secondary antibody (Invitrogen). All incubations were at room temperature and sections were washed three times for $5 \mathrm{~min}$ each in PBS between each step. Sections were mounted in an anti-fading reagent with 4',6-diamidino-2-phenylindole (DAPI) (Invitrogen). Control slides were included in each analysis in which non-immune serum was substituted for primary antibodies and secondary antibodies individually.

\section{Tissue Microarrays}

Lung cancer tissue microarray slides were obtained from Imgenex (San Diego, CA, Cat\# IMH-358 and IMH305), US Biomax (Rockville, MD, Cat\# LC951) and Cybrdi (Rockville, MD, cat\# CC04-01). There were a total of 202 cases of primary lung cancer, 16 metastatic carcinomas and 34 normal or non-tumor adjacent lung tissues. Patients included 160 males and 42 females between 26 and 81 years of age, with a median age of 59. The histology subtypes included 53 adenocarcinomas (Ad), 20 bronchioloalveolar carcinomas (BAC), 4 adenosquamous carcinomas (Ad-Sq), 81 squamous cell carcinomas (Sq), 15 large cell carcinomas (LCLC), 25 small cell lung carcinomas (SCLC) and 4 of other subtypes (3 mucoepidermoid carcinoma and 1 malignant mesothelioma). One hundred twenty four contained TNM stage data (Table S1).

\section{Immunohistochemistry (IHC)}

Tissue microarray slides were baked at $62^{\circ} \mathrm{C}$ for 1 $\mathrm{hr}$, deparaffinized in xylene for $15 \mathrm{~min}$, and rehydrated in $100 \%, 95 \%$ and $70 \%$ ethanol for $5 \mathrm{~min}$ each. Antigen retrieval was achieved by steaming slides for $10 \mathrm{~min}$ in $10 \mathrm{mM}$ citrate buffer, $\mathrm{pH}$ 6.0. Slides were washed three times in PBS and blocked for $1 \mathrm{hr}$ in a buffer containing $10 \%$ goat serum in PBS, and incubated overnight at $4^{\circ} \mathrm{C}$ with a 1:1,000 dilution of rat anti-Msi1 antibody $14 \mathrm{H}-1$ conjugated with biotin [45]. Slides were washed three times in PBS and antigen visualized with ABC Vectastain and DAB as substrate (Vector Labs, Burlingame, CA). Slides were counterstained with Harris-modified hematoxylin (Thermo-Fisher, Pittsburgh, PA) and mounted in Permount.

The Msi1 expression pattern criteria determined by IHC included: 1) 'diffuse' when almost all cells expressed the antigen, 2) 'focal' when isolated groups of $\mathrm{Msi1}^{+}$cells were seen within a histological section and 3) 'scattered staining' when single cells were $\mathrm{Msi1}^{+}$. The level of Msil expression in lung cancer tissue was categorized by diffusion scores and intensity scores. The criteria of Msil diffusion expression scores were: 0 , negative; 1 , $1-30 \%$ positive cells, $2,31-60 \%$ positive cells, and 3 , $>60 \%$ positive cells. Intensity scores were: 0 , negative,
1, low intensity, 2, median intensity and 3, high intensity. Four high power fields (400X) were randomly chosen for counting $\mathrm{Msi1}^{+}$cells in each core of the slide. A total of $\sim 1000$ cells per core per patient were analyzed. All slides were reviewed by one pathologist (Linnoila RI, M.D.) and one well-trained researcher in pathology (Wang XY, M.D., $\mathrm{Ph}$.D.) blinded to the patients' clinical information.

\section{Clinical samples from bronchoscope biopsy}

This study is a prospective analysis of 102 patients with histologically proven lung cancer and 16 non-cancer patients treated at Guilin Medical University Hospital and Affiliated Nan Xi Shan Hospital in China from March, 2011 to December, 2011. All cases were newly diagnosed and had not received anti-cancer therapy. The study was approved by the Guilin Medical University Review Board, and informed consent was obtained from all patients undergoing the procedures prescribed by the university ethics committee.

\section{Lung cancer patients}

There were a total of 102 lung cancer patients comprising 84 males and 18 females ranging from 29 to 80 years of age $($ median $=59.5)$. Seventy-seven cases were non-small cell lung cancer (NSCLC) and 25 cases small cell lung cancer (SCLC); 60 patients were smokers. After a clinical examination, patients underwent CT scans for staging of the tumor. On the basis of clinical and radiological findings, 89 cases had staging data, and consisted of 27 cases of stage IV, 51 cases of stage III, 4 cases of stage II and 7 cases of stage I cancer (Table 2).

\section{Non-cancer control group}

The control group consisting of 16 patients undergoing biopsy by fiberoptic bronchoscopy included 6 cases of tuberculosis, 6 cases with a diagnosis of bronchitis, 2 cases of pneumonia, 1 case of tuberculous pleurisy and 1 case of brochiectasis (Supplementary Table 2).

\section{Biopsy}

All patients underwent bronchoscopy and at least 5 biopsy specimens were obtained. One to two specimens were snap frozen and stored at $-80^{\circ} \mathrm{C}$ for reverse transcription polymerase chain reaction (RT-PCR) analysis. The remaining specimens were immersed in buffered formalin for histopathological evaluation. RTPCR was conducted after confirmation of the diagnosis. 


\section{Semi-quantitative RT-PCR}

Total RNA was isolated from the biopsy tissue using Trizol reagent (TakaRa Bio Inc., Dalian, China) according to the manufacturer's instructions. One microgram of template RNA was reverse transcribed to cDNA using PrimeScript II 1st Strand cDNA Synthesis Kit (TakaRa). PCR was carried out on $1 \mu \mathrm{l}$ of the cDNA template, 1 $\mu \mathrm{l}(10 \mu \mathrm{M})$ forward/reverse primers using $2 \mathrm{X}$ GoldStar Taq MasterMix (CoWin Bioscience, Bejing, China) in final volume of $25 \mu$. The DNA thermal cycler conditions used were $94^{\circ} \mathrm{C}$ for $5 \mathrm{~min}$ (pre-denature), and 35 cycles of $94^{\circ} \mathrm{C}$ for $1 \mathrm{~min}, 56.2^{\circ} \mathrm{C}$ (for Msi1) or $62^{\circ} \mathrm{C}$ (for beta-actin) for $30 \mathrm{~s}$ and $72^{\circ} \mathrm{C}$ for $45 \mathrm{~s}$, followed by a final extension of $72^{\circ} \mathrm{C}$ for $2 \mathrm{~min}$. Six $\mu 1$ of each of Msil and $\beta$-actin PCR-amplified product was mixed and fractionated on a $2 \%$ agarose gel, which was then visualized by ethidium bromide staining using a JS-780 Gel Image Analysis System (Peiqing Sci Tech., Ltd, Shanghai, China). The primer pairs yield PCR products of $306 \mathrm{bp}$ for Msi1 and 417 bp for $\beta$-actin, respectively. Primers for Msil were: 5'-GCT CGA CTC CAA AAC AAT TGA CC-3' (forward) and 5'-GGC TGA GCT TTC TTA CAT TCC AC-3' (reverse). Primer sequences for $\beta$-actin were: 5'-ACA GAG CCT CGC CTT TGC CGA TC-3'(forward) and 5'TGG GTC ATC TTC TCG CGG TTG G-3'(reverse).

For quantitation of RT-PCR products, the integrated density of the PCR bands in the agarose gel was measured by a JS-780 Gel Image Analysis System. The relative level of Msi1 expression $=$ Msi1 integrated density $/ \beta$ actin integrated density. mRNA was obtained from cells in exponential growth and the PCR cycle numbers of Msi1 and $\beta$-actin during were based on the integrated density from 20 to 40 cycles.

\section{Statistical analysis}

Data were analyzed with the Chi-Square test, Student's t test, Whitney-Mann U test and Kruskal-Wallis $\mathrm{H}$ test. Data were expressed as mean \pm standard deviation (SD) or percentage (\%). A p-value of less than 0.05 was considered statistically significant. All statistical analyses were performed with the Statistical Package for Social Sciences (SPSS, version 11.0, Chicago, IL, USA).

\section{ACKNOWLEDGEMENTS}

This work was supported by Intramural Research Program of the National Institutes of Health, National Cancer Institute, Key Research Project Grant 2012003, Guangxi Health Department, and a grant from Uniting Against Lung Cancer, New York, NY.

\section{REFERENCES}

1. Jemal A, Bray F, Center MM, Ferlay J, Ward E and Forman D. Global cancer statistics. CA Cancer J Clin. 2011; 61(2):69-90.

2. Siegel R, Naishadham D and Jemal A. Cancer statistics, 2012. CA Cancer J Clin. 2012; 62(1):10-29.

3. El-Bayoumi E and Silvestri GA. Bronchoscopy for the diagnosis and staging of lung cancer. Seminars in respiratory and critical care medicine. 2008; 29(3):261-270.

4. Maldonado F and Jett JR. Advances in the diagnosis of lung cancer: contribution of molecular biology to bronchoscopic diagnosis. Curr Opin Pulm Med. 2010; 16(4):315-320.

5. Wigle DA. Personalized therapy for non-small cell lung cancer: hype or clinical reality? Semin Thorac Cardiovasc Surg. 2011; 23(1):30-35.

6. Herbst RS and Lippman SM. Molecular signatures of lung cancer--toward personalized therapy. N Engl J Med. 2007; 356(1):76-78.

7. Yu T, Zhao LN, Lan SY, Fan MJ, Gong Y, Shi L, Yuan YH, Huang KH and Chen QK. Musashil expression cells derived from mouse embryonic stem cells can be enriched in side population isolated by fluorescence activated cell sorter. BMC cell biology. 2011; 12:47.

8. Glazer RI, Wang XY, Yuan H and Yin Y. Musashi1: a stem cell marker no longer in search of a function. Cell cycle. 2008; 7(17):2635-2639.

9. Glazer RI, Vo DT and Penalva LO. Musashil: an RBP with versatile functions in normal and cancer stem cells. Front Biosci. 2012; 17:54-64.

10. Okano H, Kawahara H, Toriya M, Nakao K, Shibata S and Imai T. Function of RNA-binding protein Musashi-1 in stem cells. Exp Cell Res. 2005; 306(2):349-356.

11. Galante PA, Sandhu D, de Sousa Abreu R, Gradassi M, Slager N, Vogel C, de Souza SJ and Penalva LO. A comprehensive in silico expression analysis of RNA binding proteins in normal and tumor tissue: Identification of potential players in tumor formation. RNA biology. 2009; 6(4):426-433.

12. Imai $T$, Tokunaga $A$, Yoshida $T$, Hashimoto M, Mikoshiba K, Weinmaster G, Nakafuku M and Okano H. The neural RNA-binding protein Musashil translationally regulates mammalian numb gene expression by interacting with its mRNA. Mol Cell Biol. 2001; 21(12):3888-3900.

13. Battelli C, Nikopoulos GN, Mitchell JG and Verdi JM. The RNA-binding protein Musashi-1 regulates neural development through the translational repression of p21WAF-1. Mol Cell Neurosci. 2006; 31(1):85-96.

14. Kawahara $H$, Imai $T$, Imataka $H$, Tsujimoto $M$, Matsumoto $\mathrm{K}$ and Okano H. Neural RNA-binding protein Musashi1 inhibits translation initiation by competing with eIF4G for PABP. J Cell Biol. 2008; 181(4):639-653.

15. Horisawa $\mathrm{K}$, Imai $\mathrm{T}$, Okano $\mathrm{H}$ and Yanagawa $\mathrm{H}$. 3'-Untranslated region of doublecortin mRNA is a binding 
target of the Musashi1 RNA-binding protein. FEBS Lett. 2009; 583(14):2429-2434.

16. Kuwako K, Kakumoto K, Imai T, Igarashi M, Hamakubo T, Sakakibara S, Tessier-Lavigne M, Okano HJ and Okano H. Neural RNA-binding protein Musashil controls midline crossing of precerebellar neurons through posttranscriptional regulation of Robo3/Rig-1 expression. Neuron. 2010; 67(3):407-421.

17. Spears E and Neufeld KL. Novel double-negative feedback loop between adenomatous polyposis coli and Musashi1 in colon epithelia. J Biol Chem. 2011; 286(7):4946-4950.

18. de Sousa Abreu R, Sanchez-Diaz PC, Vogel C, Burns SC, Ko D, Burton TL, Vo DT, Chennasamudaram S, Le SY, Shapiro BA and Penalva LO. Genomic analyses of musashil downstream targets show a strong association with cancer-related processes. J Biol Chem. 2009; 284(18):12125-12135.

19. Wang T, Ong CW, Shi J, Srivastava S, Yan B, Cheng CL, Yong WP, Chan SL, Yeoh KG, Iacopetta B and Salto-Tellez M. Sequential expression of putative stem cell markers in gastric carcinogenesis. Br J Cancer. 2011; 105(5):658-665.

20. Liu DC, Yang ZL and Jiang S. Identification of musashi-1 and ALDH1 as carcinogenesis, progression, and poor-prognosis related biomarkers for gallbladder adenocarcinoma. Cancer biomarkers : section A of Disease markers. 2010; 8(3):113-121.

21. Fan LF, Dong WG, Jiang CQ, Xia D, Liao F and Yu QF. Expression of putative stem cell genes Musashi-1 and betal-integrin in human colorectal adenomas and adenocarcinomas. Int J Colorectal Dis. 2010; 25(1):17-23.

22. Gotte M, Wolf M, Staebler A, Buchweitz O, Kelsch R, Schuring AN and Kiesel L. Increased expression of the adult stem cell marker Musashi-1 in endometriosis and endometrial carcinoma. J Pathol. 2008; 215(3):317-329.

23. Moreira AL, Gonen M, Rekhtman N and Downey RJ. Progenitor stem cell marker expression by pulmonary carcinomas. Mod Pathol. 2010; 23(6):889-895.

24. Wang XY, Penalva LO, Yuan H, Linnoila RI, Lu J, Okano $\mathrm{H}$ and Glazer RI. Musashi1 regulates breast tumor cell proliferation and is a prognostic indicator of poor survival. Molecular cancer. 2010; 9:221-232.

25. Wang XY, Yin Y, Yuan H, Sakamaki T, Okano H and Glazer RI. Musashil modulates mammary progenitor cell expansion through proliferin-mediated activation of the Wnt and Notch pathways. Mol Cell Biol. 2008; 28(11):35893599 .

26. Sanchez-Diaz PC, Burton TL, Burns SC, Hung JY and Penalva LO. Musashil modulates cell proliferation genes in the medulloblastoma cell line Daoy. BMC cancer. 2008; $8: 280$.

27. Bertolini G, Roz L, Perego P, Tortoreto M, Fontanella E, Gatti L, Pratesi G, Fabbri A, Andriani F, Tinelli S, Roz E, Caserini R, Lo Vullo S, Camerini T, Mariani L, Delia D, et al. Highly tumorigenic lung cancer CD133+ cells display stem-like features and are spared by cisplatin treatment. Proc Natl Acad Sci U S A. 2009; 106(38):16281-16286.

28. Pine SR, Ryan BM, Varticovski L, Robles AI and Harris CC. Microenvironmental modulation of asymmetric cell division in human lung cancer cells. Proc Natl Acad Sci U S A. 2010; 107(5):2195-2200.

29. Eramo A, Lotti F, Sette G, Pilozzi E, Biffoni M, Di Virgilio A, Conticello C, Ruco L, Peschle C and De Maria R. Identification and expansion of the tumorigenic lung cancer stem cell population. Cell Death Differ. 2008; 15(3):504514.

30. McGill MA, Dho SE, Weinmaster G and McGlade CJ. Numb regulates post-endocytic trafficking and degradation of Notch1. J Biol Chem. 2009; 284(39):26427-26438.

31. McGill MA and McGlade CJ. Mammalian numb proteins promote Notch1 receptor ubiquitination and degradation of the Notch1 intracellular domain. J Biol Chem. 2003.

32. Gordon MD and Nusse R. Wnt signaling: multiple pathways, multiple receptors, and multiple transcription factors. J Biol Chem. 2006; 281(32):22429-22433.

33. Gu Y, Fu J, Lo PK, Wang S, Wang Q and Chen H. The effect of B27 supplement on promoting in vitro propagation of Her2/neu-transformed mammary tumorspheres. Journal of Biotech Research. 2011; 3:7-18.

34. Ravindran G and Devaraj H. Aberrant expression of CD133 and musashi-1 in preneoplastic and neoplastic human oral squamous epithelium and their correlation with clinicopathological factors. Head Neck. 2012; 34(8):11291135.

35. Vo DT, Subramaniam D, Remke M, Burton TL, Uren PJ, Gelfond JA, de Sousa Abreu R, Burns SC, Qiao M, Suresh U, Korshunov A, Dubuc AM, Northcott PA, Smith AD, Pfister SM, Taylor MD, et al. The RNA-binding protein Musashil affects medulloblastoma growth via a network of cancer-related genes and is an indicator of poor prognosis. Am J Pathol. 2012; 181(5):1762-1772.

36. Muto J, Imai T, Ogawa D, Nishimoto Y, Okada Y, Mabuchi Y, Kawase T, Iwanami A, Mischel PS, Saya H, Yoshida $\mathrm{K}$, Matsuzaki $\mathrm{Y}$ and Okano H. RNA-binding protein Musashi1 modulates glioma cell growth through the posttranscriptional regulation of Notch and PI3 kinase/Akt signaling pathways. PloS one. 2012; 7(3):e33431.

37. Vo DT, Abdelmohsen K, Martindale JL, Qiao M, Tominaga K, Burton TL, Gelfond JA, Brenner AJ, Patel V, Trageser $\mathrm{D}$, Scheffler B, Gorospe M and Penalva LO. The oncogenic RNA-binding protein Musashi1 is regulated by HuR via mRNA translation and stability in glioblastoma cells. Molecular cancer research : MCR. 2012; 10(1):143-155.

38. Li D, Peng X, Yan D, Tang H, Huang F, Yang Y and Peng Z. Msi-1 is a predictor of survival and a novel therapeutic target in colon cancer. Ann Surg Oncol. 2011; 18(7):20742083.

39. Sureban SM, May R, George RJ, Dieckgraefe BK, McLeod HL, Ramalingam S, Bishnupuri KS, Natarajan G, 
Anant S and Houchen CW. Knockdown of RNA binding protein musashi-1 leads to tumor regression in vivo. Gastroenterology. 2008; 134(5):1448-1458.

40. Nishimoto $\mathrm{Y}$ and Okano H. New insight into cancer therapeutics: induction of differentiation by regulating the Musashi/Numb/Notch pathway. Cell Res. 2010; 20(10):1083-1085.

41. Rezza A, Skah S, Roche C, Nadjar J, Samarut J and Plateroti $\mathrm{M}$. The overexpression of the putative gut stem cell marker Musashi-1 induces tumorigenesis through Wnt and Notch activation. J Cell Sci. 2010; 123(Pt 19):3256-3265.

42. Katoh $M$ and Katoh M. NUMB is a break of WNT-Notch signaling cycle. Int J Mol Med. 2006; 18(3):517-521.

43. Kaneko Y, Sakakibara S, Imai T, Suzuki A, Nakamura Y, Sawamoto K, Ogawa Y, Toyama Y, Miyata T and Okano H. Musashil: an evolutionally conserved marker for CNS progenitor cells including neural stem cells. Dev Neurosci. 2000; 22(1-2):139-153. 